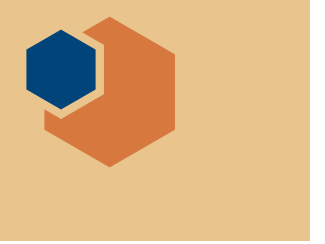

\title{
Senate bill boosts US competitiveness
}

I n early June, the US Senate passed the United States Innovation and Competition Act (USICA), formerly known as the Endless Frontiers Act. It will next go to the US House of Representatives where it is expected to pass and be signed into law. Originally introduced last year by Senators Chuck Schumer (D-N.Y.) and Todd Young (R-Ind.), the bill is a USD\$200 billion proposal aimed at expanding domestic R\&D funding in several key areas including semiconductors, drones, wireless broadband, and artificial intelligence over the next five years. It is also designed to make the United States economically competitive.

IBM Chair and CEO Arvind Krishna calls USICA "a visionary piece of legislation that recognizes the potential for scientific discovery to solve society's biggest challenges and encourages the

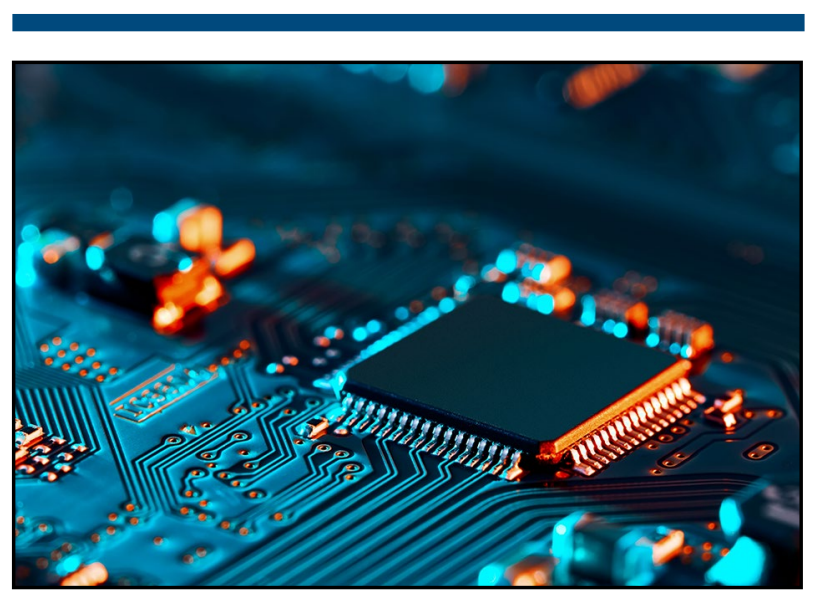

type of public-private collaboration that took humanity to the moon," according to a news release; "I applaud Majority Leader Schumer's leadership, and that of Senators [John] Cornyn and Young, in this bipartisan push to harness emerging technology for societal progress and to expand economic opportunity."

One part of the bill, called the Creating Helpful Incentives to Produce Semiconductors (CHIPS) Act, allocates USD\$52 billion in emergency supplemental appropriations for the National Defense Authorization Act for the upcoming fiscal year. These funds are directed toward incentive programs to produce semiconductors in the United States. The bill also includes USD $\$ 1.5$ billion for the Public Wireless Supply Chain Innovation Fund to create similar incentive programs for wireless broadband. Additionally, the legislation establishes a Directorate for Technology and Innovation within the National Science Foundation (NSF), in order to direct research, development, and commercialization support in "key technology focus areas," such as artificial intelligence or drones.

USICA contains several higher education provisions to facilitate R\&D in areas such as robotics, artificial intelligence, and advanced energy sources. These provisions seek to expand the federal government's role in incentivizing higher education institutions to support these areas and also facilitate diversity in the sciences. Under the bill, USD\$5.22 billion has been authorized for FY 2022-FY 2026 for a new science-technology-engineering-mathematics (STEM) scholarship fund. The scholarships could be used for postdoctoral programs, graduate fellowships, undergraduate courses, and internship programs, for example, with an emphasis on supporting underrepresented populations in STEM.

USICA also creates a new academic technology transfer fund to translate scientific discoveries into a final product or service. This fund is authorized for USD\$4.06 billion from FY 2022 to FY 2026. The director of NSF, in coordination with the National Institute of Standards and Technology (NIST), would make grants to facilitate technology transfer between the private sector and higher education institutions.

"I applaud the US Senate for its bipartisan commitment to strengthening the domestic semiconductor supply chain.... The USICA not only boosts semiconductor manufacturing - but literally impacts every single one of our lives," said Thomas Caulfield, CEO of GlobalFoundries, in a news release.

Damon Dozier

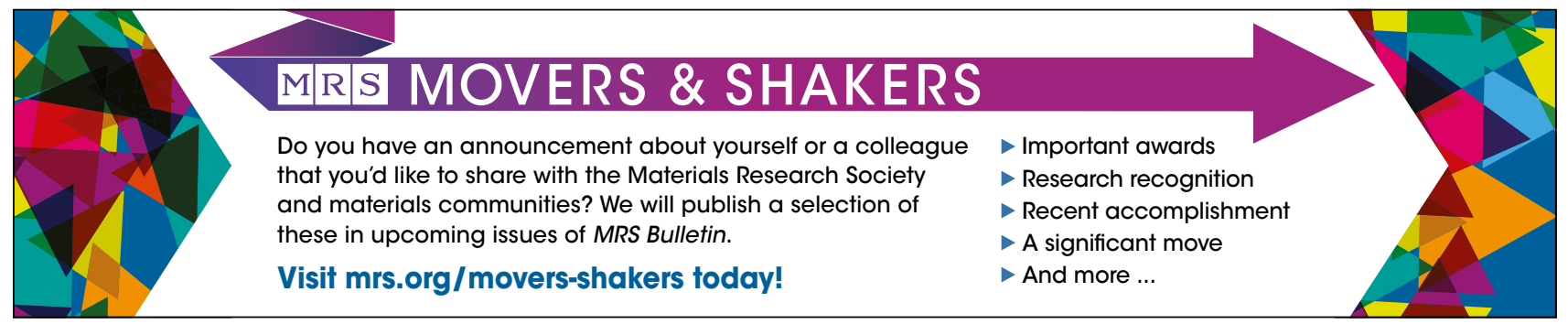

